Jones, N.F., WAlker, G., Ruthyen, C.R.J. \& SANdler, M. (1968) Alpha-methyl-p-thyrosine in the management of phaeochromocytoma. Lancet, ii, 1105.

Kraft, A.R., Tompkins, R.K. \& Zollinger, R.M. (1970) Recognition and management of the diarrheal syndrome caused by non-beta islet cell tumours of the pancreas. American Journal of Surgery, 119, 163.

Melmon, K.L. (1968) The endocrinologic manifestations of the carcinoid tumour. In: Textbook of Endocrinology (Ed. by R. H. Williams). W. B. Saunders, Co., Philadelphia, London, Toronto.

OAtes, J.A. \& Butler, T.C. (1967) Pharmacologic and endocrine aspects of carcinoid syndrome. Advances in Pharmacology, 5, 109.

Pedersen, R.A. \& Brown, J.C. (1972) Inhibition of histamine-pentagastrin and insulin-stimulated canine gastric secretion by pure 'gastric inhibitory polypeptide'. Gastroenterology, 62, 393.

Polak, J.M., Stagg, B. \& Pearce, A.G.E. (1972) Two types of Zollinger-Ellison syndrome immunofluorescent cytochemical and ultrastructural studies of the antral and pancreatic gastrin cells in different clinical states. Gut, 13, 501 .
Pearce, A.G.E. (1969) The cytochemistry and ultrastructure of polypeptide hormone-producing cells of the Apud Series and the embryologic, physiologic and pathologic implications of the concept. Journal of Histochemistry and Cytochemistry, 17, 303.

Rosenstein, B.J. \& Engelman, K. (1963) Diarrhea in a child with a catecholamine-secreting ganglioneuroma. Case report and review of the literature. Journal of Paediatrics. 63, 217.

SANDler, M., Karim, S.M.M. \& Williams, E.D. (1968) Prostaglandins in amine-peptide-secreting tumours. Lancet. ii, 1053.

Verner, J.V. \& Morrison, A.B. (1958) Islet cell tumor and a syndrome of refractory watery diarrhea and hypokalemia. American Journal of Medicine, 25, 374.

Williams, E.D., Karim, S.M.M. \& Sandler, M. (1968) Prostaglandin secretion by medullary carcinoma of the thyroid. Lancet, i, 22.

Zollinger, R.M. \& Ellison, E.H. (1955) Primary peptic ulcerations of jejunum associated with islet cell tumours of pancreas. Annals of Surgery, 142, 709.

Postgraduate Medical Journal (June 1975) 51, 419-422.

\title{
Skin metastases in carcinoma of the stomach
}

\author{
B. A. ADAM \\ M.B.B.S., M.R.C.P. \\ R. Murugasu \\ M.B.B.S. \\ Departments of Medicine and Pathology, Faculty of Medicine, University of Malaya, \\ Kuala Lumpur
}

\section{Summary}

A patient who presented with cutaneous nodules had carcinoma of the stomach. The histochemistry of the dermal infiltrate gave a clue to the primary site. Autopsy revealed metastases in all the organs of the chest and abdominal cavity. The invasion of the testis and the gingiva was unusual. Cutaneous metastases from a visceral malignancy probably indicate an early fatal termination.

Metastatic lesions to the skin from internal malignancies are rare and the incidence has been reported to vary from one to $2.7 \%$ (Gates, 1937; Beerman, 1957). Most reports quote lung and the breast as the primary site of malignancy although other sites including the stomach are not uncommon. The metastases, either single or multiple, may be the initial manifestations of the internal malignancy.

\section{Case report}

\section{History and physical examination}

Four months before admission to hospital, a 32year-old Indian male developed nodular eruptions initially on the forehead and the face (Fig. 1) and later on the upper part of the trunk. His appetite

Correspondence: Dr R. Murugasu, Department of Pathology, Medical Faculty, University of Malaya, Kuala Lumpur, Malaysia. became poor and he had lost some weight. There were no other symptoms. Clinical examination showed a well nourished individual. Nodules varying in size from 0.5 to $3 \mathrm{~cm}$ were found on the face, scalp, neck, chest wall, upper arms, and the back. They were attached to the skin and non-tender. The skin over the nodules was intact. In addition there were a few plaques of infiltrated skin with dilated follicular openings on the chin and the back of the neck. Oral, lingual and pharyngeal mucosa were intact but the gingiva showed gross hypertrophy without any evidence of infection (Fig. 2). There was no lymphadenopathy and the abdominal viscera were not palpable. Skin and gingival biopsies and a barium meal X-ray were done. On the fourth week of his stay in hospital, nodules appeared on the abdominal wall and enlarged lymph nodes were felt in the neck and the left axilla. Ascites soon appeared and the fluid was cloudy yellow. In the sixth week, he developed epigastric pain with three episodes of haematemesis and melaena. His right testis and the spermatic cord were found to be enlarged. $\mathrm{He}$ deteriorated and died at the end of the seventh week.

\section{Investigations}

Hb $14.0 \mathrm{~g} / 100 \mathrm{ml}$; WBC $3500 / \mathrm{mm}^{3}$; neutrophils $56 \%$; lymphocytes $37 \%$; eosinophils $7 \%$; ESR 13 


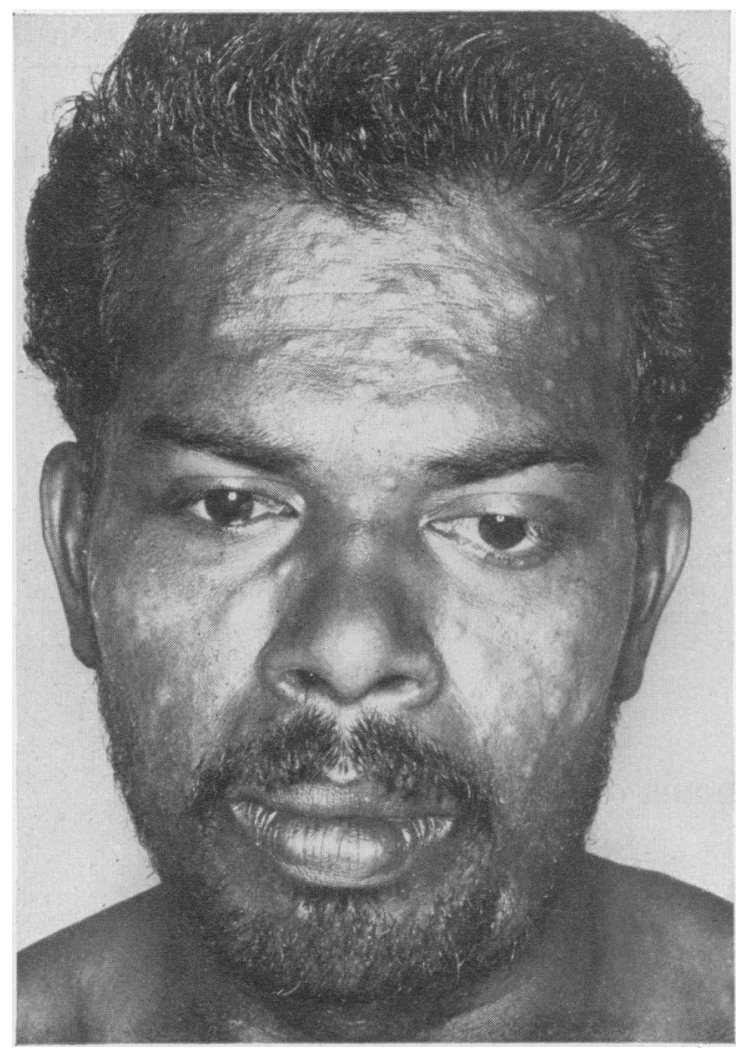

Fig. 1. Nodules of various sizes on the forehead and cheek. $\mathrm{mm}$ in $1 \mathrm{hr}$; serum iron $55 \mu \mathrm{g} \%$; bone marrow normal; serum albumin $2.9 \mathrm{~g} \%$; globulin $4.4 \mathrm{~g} \%$; bilirubin $0.7 \mathrm{mg} \%$; alkaline phosphatase 172 i.u./l (normal 30-90 i.u./1); chest and sinus X-rays were normal; barium meal showed no ulcer or growth and the lumen of the stomach appeared intact on screening.

Biopsy of the nodules from the face and the chest wall showed infiltration of the dermis by clusters of cells with vacuolated cytoplasm. PAS-positive, diastase-resistant, and mucicarmine-positive material were found in the cytoplasm of these cells. Some of them showed distinct signet ring morphology. A mild lymphocytic infiltrate and desmoplastic reaction were found around the cluster of the neoplastic cells (Fig. 3). Cytology of the peritoneal fluid showed cells with eccentric nuclei and vacuolar cytoplasm with similar histochemical staining as above.

\section{Autopsy}

The peritoneal cavity contained $3400 \mathrm{cc}$ of bloodstained ascitic fluid with few small whitish nodules on the omentum. The stomach showed features of linitis plastica (Fig. 4) with no evidence of ulceration. The mucosa of the stomach was oedematous, thickened and firmly adherent to the submucosa and, in turn, to the thickened muscular layer. The lymph nodes around the lesser and greater curvatures of the stomach were enlarged and matted together. The mucosa of the lower third of the oesophagus, the small intestine, caecum, colon, and rectum had small nodules. Both adrenals showed patchy infiltration. The lung, liver, and the heart showed no

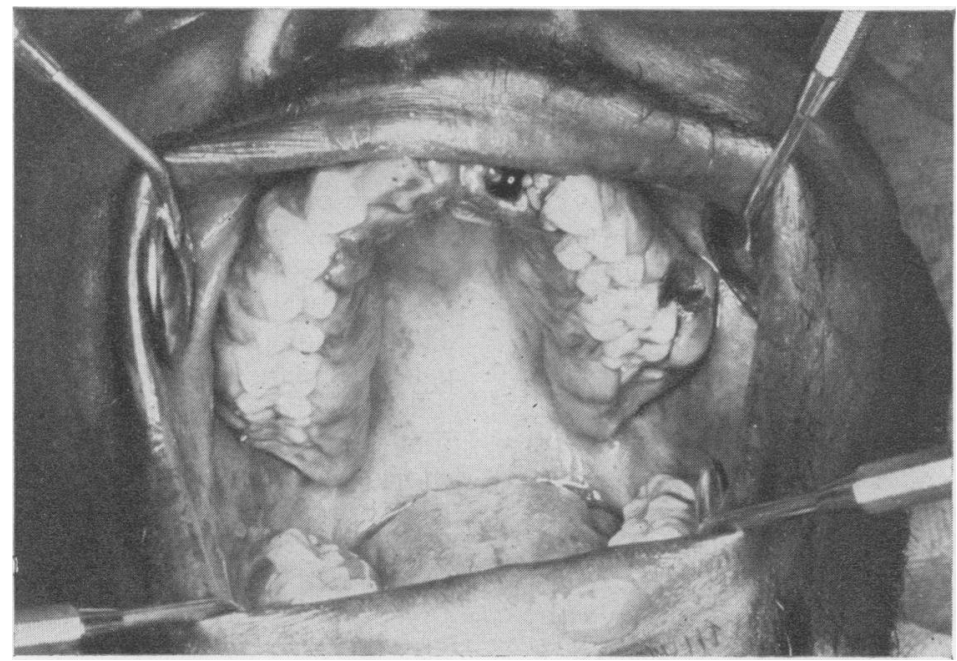

Fig. 2. Hypertrophy of the gum. The raw areas are the sites of biopsy. 


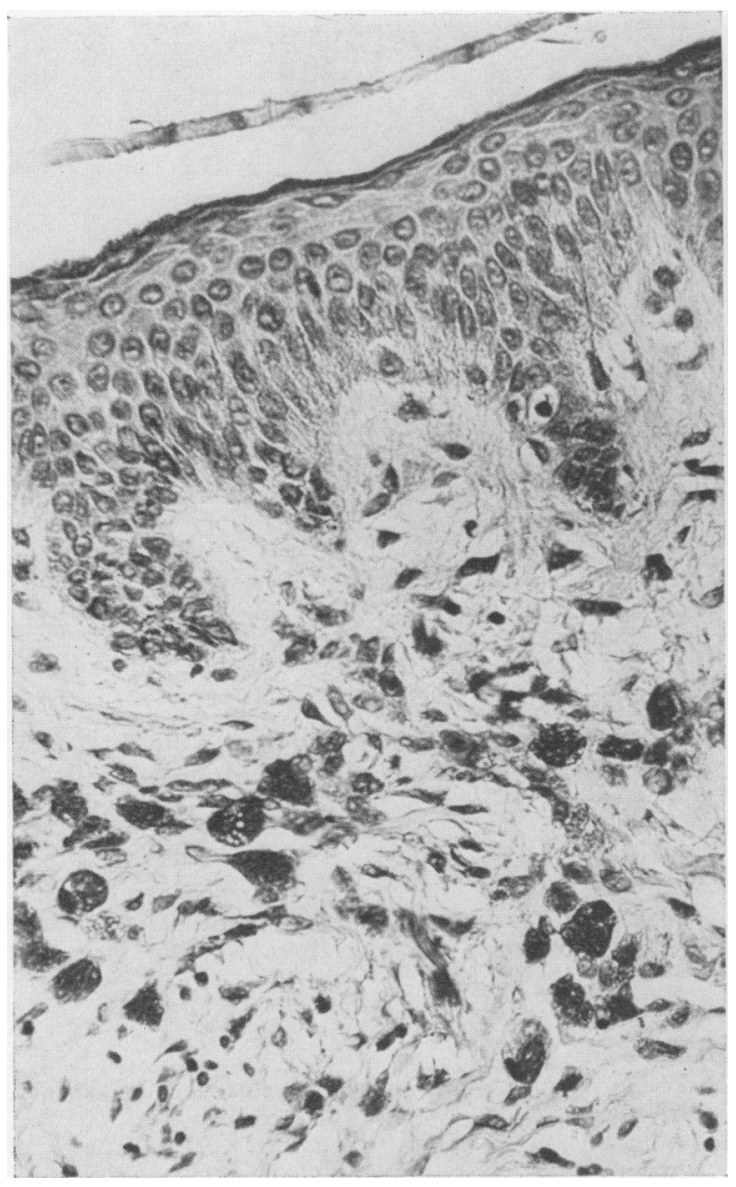

FIG. 3. Skin. Mucin containing neoplastic cells in the dermis. PAS/diastase stain. $\times 525$.

macroscopic evidence of tumour metastases. The testes were enlarged and firm.

All the layers of the stomach were infiltrated by mucin-producing signet-ring cells. The lymph nodes around the stomach, and the nodules on the mucosa of the oesophagus, small intestine, caecum, colon and rectum showed the presence of mucin-producing cells. Similar cells were also seen in the sections of the thymus, myocardium, adrenals, appendix, liver, kidney, gall bladder and sections of the ribs. The testis showed diffuse infiltrate of mucin-producing cells in the interstitium around the seminiferous tubules (Fig. 5). The lymphatic spaces in the lung showed the tumour cells.

\section{Discussion}

The stomach is considered to be one of the frequent primary malignant sites for metastases to the skin (Beerman, 1957; Lever, 1967; Rook, Wilkinson and

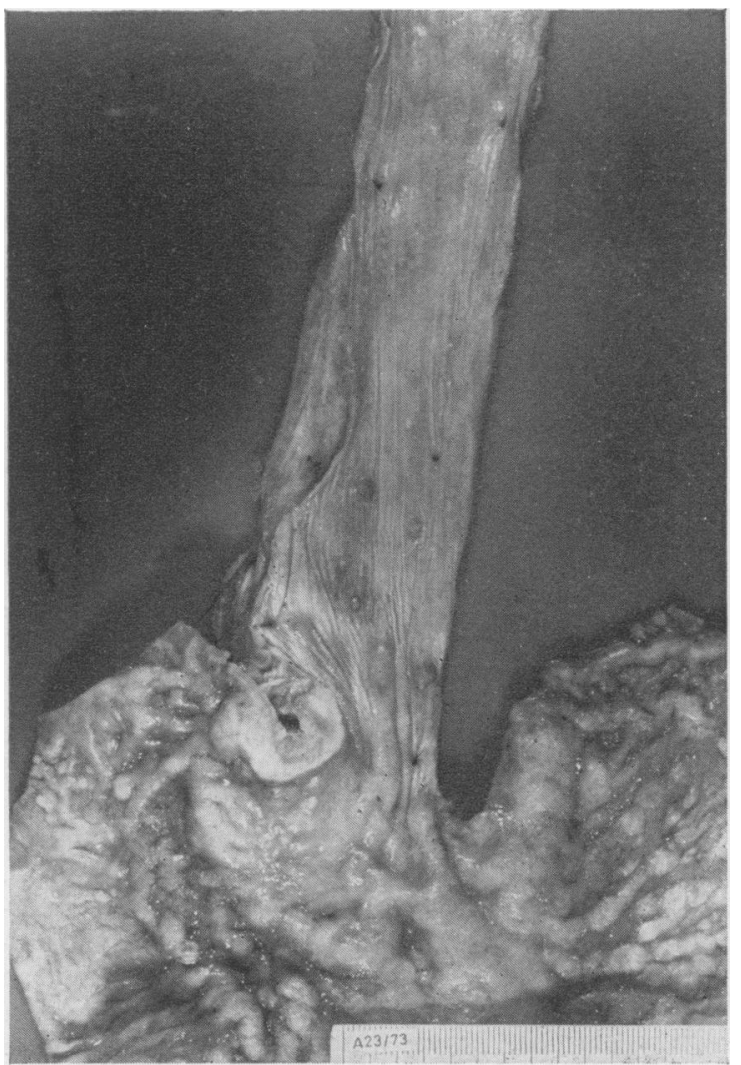

Fig. 4. Nodular plaques in the mucosa of the oesophagus. The mucosa of the stomach is thickened and there is loss of normal rugae pattern.

Ebling, 1968). The initial manifestation of the underlying malignancy in our patient was the development of skin nodules on the face and forehead. Although Brownstein and Helwig (1972) reported that cutaneous metastases may be an initial manifestation of a stomach malignancy, none of their patients who presented with cutaneous metastases on the face had carcinoma of the stomach. The clinical diagnosis in our patient was uncertain and the radiological examination was not helpful, although a clue to the primary site was suggested by the identification of mucin-producing cells in the dermis. The abdominal wall, particularly around the umbilicus, is reported as a common site for metastases from the abdominal viscera including the stomach (Gates, 1937; Reingold, 1966), but these areas were free of tumour growth in our patient until towards the terminal stage of the disease. The hypertrophy of the gingiva with microscopical evidence of malignant infiltration and the diffuse invasion of the interstitium around the seminiferous tubules were unusual and to our knowledge had not been reported earlier. 


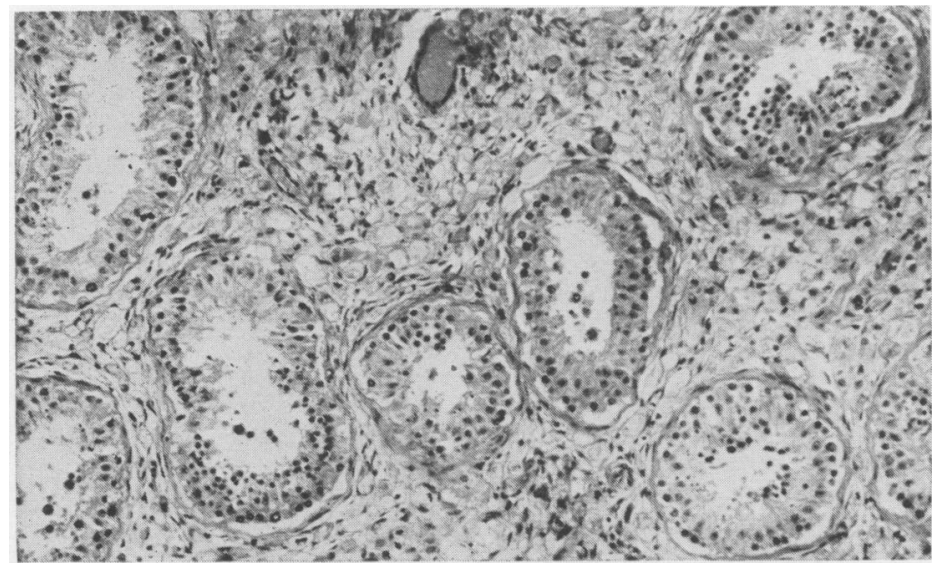

FIG. 5. Diffuse infiltrate of mucin producing, 'signetring' cells around the seminiferous tubules. HE $\times 210$.

There is usually a good correlation between the histological features of the primary malignancy and the metastatic lesions but some cutaneous metastases may show a lesser degree of differentiation than that of the primary tumour (Brownstein and Helwig, 1973). In our patient both the stomach and the metastatic sites showed mucin-producing cells with signetring morphology. The diffuse invasion of all the layers of stomach with malignant cells, resulting in linitis plastica, proves that the stomach was the primary site.

The method of spread of the cutaneous metastases from the primary is by local infiltration to the overlying skin and by lymphatic or by blood stream to the distant sites (Mehregan, 1961). It could be postulated that the blood stream was the main source of embolization in view of the involvement of every organ in the body that was examined, and the rapid progress of the disease. The presence of tumour cells in the liver and the lung probably outlines the pathway of these cells to the systemic circulation. The rapid course of the disease ending fatally within 6 months of the appearance of the skin nodules agrees with the observation that cutaneous metastases indicate a progression of the primary tumour with early fatal termination (Beerman, 1957; Mehregan, 1961; Reingold, 1966).

\section{Acknowledgments}

We would like to thank Dr F. Wang, the Department of Medical Illustration, and Mrs Helen Kok for their kind assistance.

\section{References}

BEERMAN, H. (1957) Some aspects of cutaneous malignancy. American Journal of Medical Science, 233, 456.

Brownstein, M.H. \& Helwig, E.B. (1972) Patterns of cutaneous metastases. Archives of Dermatology, 105, 862.

Brownstein, M.H. \& HelwiG, E.B. (1973) Spread of tumours to the skin. Archives of Dermatology, 107, 80.

Gates, O. (1937) Cutaneous metastases of malignant disease. American Journal of Cancer, 30, 718.

LEVER, W.F. (1967) Histopathology of the Skin, 4th edn, p. 607. Pitman Medical Publishing Co. Ltd London.

Mehregan, A.H. (1961) Metastatic carcinoma to the skin. Dermatologica, 123, 311.

Reingold, I.M. (1966) Cutaneous metastases from internal carcinoma. Cancer, 19, 162.

Rook, A., Wilkinson, D.S. \& Ebling, F.J.G. (1968) Textbook of Dermatology, Vol. 2, p. 1720. Blackwell Scientific Publications, Oxford. 